ORIGINAL ARTICLE

\title{
Theophylline and gastric emptying in very low birthweight neonates: a randomised controlled trial
}

\author{
A Gounaris, P Kokori, L Varchalama, K Konstandinidi, M Skouroliakou, N Alexiou, C Costalos
}

Arch Dis Child Fetal Neonatal Ed 2004;89:F297-F299. doi: 10.1136/adc.2003.027565

See end of article for authors' affiliations

......................

Correspondence to: Dr Gounaris, Neonatal Intensive Care Unit, Regional General Hospital, Nikea, Athens 11634 ,

Greece; gounaran@ ath.forthnet.gr

Accepted 27 May 2003
Background: Theophylline treatment causes side effects such as tachycardia, hyperglycaemia, abdominal distension, and vomiting. The latter two are probably the result of delayed gastric evacuation.

Objective: To study the effect of theophylline on gastric emptying time in preterm infants.

Patients: The subjects were 18 premature neonates with a mean (SD) birth weight of 1302 (240) $\mathrm{g}$ and a mean (SD) gestational age of 28.7 (1.9) weeks.

Main outcome measures: In each case, gastric emptying was measured on two occasions: once when the newborns were being treated with theophylline and once when they were not. Half of the cases were randomised to receive theophylline before the initial measurement. The opposite was applied for the rest. Gastric emptying was assessed ultrasonically by measuring the change in antral cross sectional area (ACSA) at regular intervals over 120 minutes.

Results: The mean (SD) ACSA half time in the newborns receiving theophylline was 52 (19) minutes compared with 37 (16) minutes in those not receiving theophylline. This difference is significant $(p<0.05)$. Conclusions: Treatment with theophylline seems to delay gastric emptying in very low birthweight neonates, and this must be taken into consideration when this drug is used to treat apnoea of prematurity. to the neonatal intensive care unit, theophylline continues to be helpful in treating apnoea of prematurity ${ }^{1-3}$ and is also often used for its prevention. ${ }^{45}$ In addition, it is useful for achieving earlier extubation in preterm infants ${ }^{6}$ and treating babies with bronchopulmonary dysplasia.

Theophylline treatment can cause the following adverse side effects in newborns, adults, and experimental animals: tachycardia, ${ }^{7}$ hyperglycaemia, gastric complications with regurgitation and vomiting, ${ }^{8}{ }^{9}$ seizures, ${ }^{10}$ increases in the basal metabolic rate, ${ }^{11}$ and calcium excretion. ${ }^{12}{ }^{13}$ Aminophylline is also a mild gastric irritant which affects gastric acid secretion when administered orally or intraperitoneally. ${ }^{14}$

The effects of theophylline on the gut system in general and on the stomach in particular were found in children to be due to reduced basal lower oesophageal sphincter pressure. ${ }^{15}$ However, there is no evidence that this is the specific cause of the general effect of theophylline on the gut of newborns.

The aim of our study was to investigate whether theophylline treatment has any effect on the gastric emptying time of preterm newborns.

\section{MATERIALS AND METHODS}

The subjects were 18 premature neonates ( 12 boys and six girls) with a mean (SD) birth weight of 1302 (240) g and a mean (SD) gestational age of 28.7 (1.9) weeks. None were small for gestational age. Corticosteroids had been administered once or twice antenatally in 13 cases. The median Apgar score for the subjects was 7 (range 3-8) in the first minute and 8 (range 6-9) in the fifth minute. Ten developed hyaline membrane disease, and two had transient tachypnoea. Four of them developed bronchopulmonary dysplasia $\left(\mathrm{O}_{2}\right.$ supplement $>28$ days of life).

Theophylline was used for treatment rather than for prevention, according to our protocol. We used theophylline after the first apnoea attack, regardless of the severity of the episode, with a loading intravenous dose of $5 \mathrm{mg} / \mathrm{kg}$ and thereafter an intravenous dose of $1.5 \mathrm{mg} / \mathrm{kg} / 8 \mathrm{~h}$ for two to three weeks depending on the baby's maturity. These newborns did not require any other treatment apart from theophylline. Gastric emptying was measured in every newborn on two occasions, once during theophylline treatment and once during a period of no theophylline treatment. Half of the cases were randomised to receive theophylline before the initial measurement. Randomisation was carried out by using sealed envelopes. The opposite was applied for the rest. The second measurement in every newborn was performed two to three days after the first. Gastric emptying was first measured at 18 (7) days and then at 21 (8) days (mean (SD)).

Several methods have been proposed for the measurement of gastric emptying. ${ }^{16}{ }^{17}$ Newells and colleagues ${ }^{17}$ devised an ultrasound method, which is simple, with minimal handling of the newborn, and is performed near the cot without causing any discomfort. The only drawback is that it is time consuming. The transducer takes regular measurements of the antral cross sectional area (ACSA) for a period of up to 120 minutes, depending on the gastric emptying time. The measurements are made with the newborn in a right lateral position; transverse sections of the pyloric antrum are taken, with the vertebral column and the origin of the superior mesenteric artery used as guiding points.

In our study, the first measurement was taken before a milk feed. After feeding, measurements were taken every 10 minutes for the first 30 minutes and thereafter every 30 minutes, a total of seven measurements (in about two hours). The newborns were stable for the duration of the measurements.

On both occasions the newborn was given the same quantity of a preterm formula containing $81 \mathrm{kcal} / 100 \mathrm{ml}$ milk, which corresponded to at least two thirds of the total daily fluid requirement ( $>120 \mathrm{ml} / \mathrm{kg} /$ day; median $15 \mathrm{ml} / \mathrm{kg}$ / $2 \mathrm{~h}$, range 11-17). Throughout the study, infants were observed for gastric residue, regurgitation, vomiting, and abdominal dissention. Gastric aspirates were measured every four hours before the feed. A gastric aspirate of more than $30 \%$ of the previous four hour feed volume was regarded as significantly large. Abdominal girth was also measured, before feeds, at 12 hour intervals. An increase in abdominal 

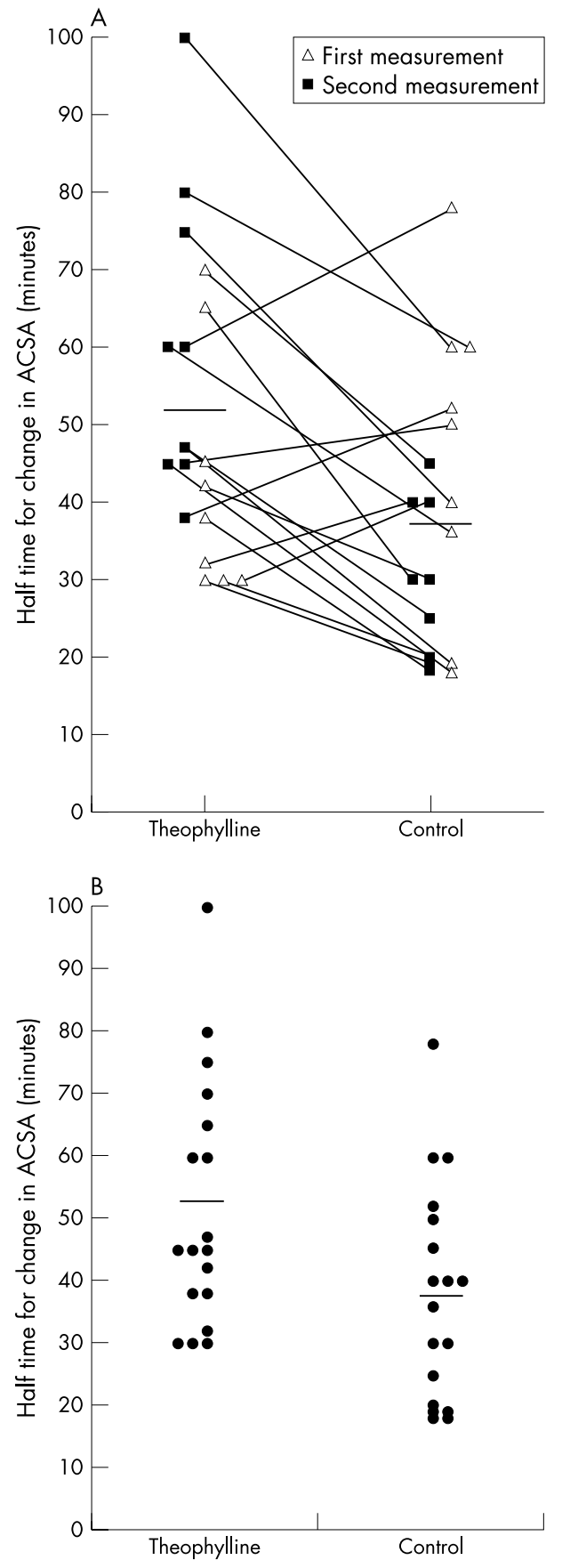

Figure 1 Change in antral cross sectional area (ACSA), as a measure of gastric emptying, in neonates receiving or not receiving theophylline. The mean values of the two measurements are shown (solid horizontal lines).

girth of more than $1.5 \mathrm{~cm}$ within one 12 hour period was considered abnormal. Any episodes of vomiting/regurgitation and bile stain aspirates during the study were recorded. The doctor who performed the ultrasound was not aware of whether the newborn was receiving theophylline when the measurements were taken.

Approval was given for the study by the ethics committee of our hospital, and informed parental consent was also obtained.

As each newborn served as his/her own control, necessitating two groups of measurements, Student's paired $t$ test was chosen for statistical analysis.

\section{RESULTS}

The half time for gastric emptying (measured as the change in ACSA) was longer in 13 of the 18 subjects during theophylline treatment; in the remaining five, it was longer when they were not receiving theophylline (fig 1). The mean (SD) half times in the neonates receiving theophylline was 52 (19) minutes $v 37$ (16) minutes in those not receiving theophylline. This difference is significant $(\mathrm{p}<0.05)$.

Serum theophylline concentrations in newborns treated with theophylline varied between 6 and $11 \mu \mathrm{g} / \mathrm{ml}$ and therefore fell within normal therapeutic concentrations. There was no correlation between theophylline concentration and gastric emptying time. Theophylline concentrations during gastric emptying measurements in those newborns that were not receiving theophylline at the time were less than $2 \mu \mathrm{g} / \mathrm{ml}$. Vomiting and other gut complications were no more prevalent when the subjects were receiving theophylline than when they were not.

\section{DISCUSSION}

Recently there have been several meta-analysis studies on the use of theophylline in newborns. They show that treatment for apnoea of prematurity is only effective in the first seven days. ${ }^{19}$ Moreover, results on the use of theophylline for prevention of apnoeas are not convincing. ${ }^{20}$ However, theophylline does help in weaning preterm infants off the ventilator, $^{21}$ especially in those with birth weight $<1000 \mathrm{~g}$ and age $<7$ days. The side effects of theophylline (seizures, gut complications, hyperglycaemia, tachycardia, decreased cerebral blood flow $)^{22} 23$ often appear at blood concentrations above $20 \mu \mathrm{g} / \mathrm{ml}$ and are rare at concentrations below $13 \mu \mathrm{g} /$ $\mathrm{ml}^{23}{ }^{24}$ Patients have occasionally exhibited gastrointestinal side effects, including vomiting, at theophylline concentrations of less than $10 \mu \mathrm{g} / \mathrm{ml}^{25}{ }^{26}$ Concern has also been expressed about theophylline treatment in premature infants at risk of necrotising enterocolitis. ${ }^{27}$

Another important effect of theophylline treatment is the slowing of gastrointestinal motility, which has been clearly shown in guinea pig taenia coli. ${ }^{28}$ Our results tend to confirm this animal trial, in that there was prolonged gastric emptying in most of the premature infants receiving theophylline. The mean half time was significantly longer, and 13 of the 18 subjects showed delayed gastric emptying time during theophylline treatment, despite the fact that all had normal theophylline concentrations. None had symptoms such as vomiting or gagging any more often when they were receiving theophylline than when they were not; this applied even to the newborn with the most delayed gastric emptying time.

All our subjects received theophylline intravenously because of the increased gastrointestinal side effects of per os administration. ${ }^{29}$ From our results it would therefore be fair to conclude that intravenous theophylline at therapeutic blood concentrations often affects gastric motility, as it does in experimental animals, but this is not always followed by obvious clinical symptoms. The delayed gastric emptying may be related to the effect of the drug on CAMP, calcium influx, or potassium induced membrane depolarization. ${ }^{28}$

In view of our results, account should be taken of the gastric emptying delay that often occurs with theophylline use. It is therefore advisable to use this drug with caution if there are signs of enteral feeding intolerance in premature neonates, and also in conditions such as gastro-oesophageal reflux, which are known to cause delayed gastric emptying.

\section{Authors' affiliations}

A Gounaris, K Konstandinidi, N Alexiou, C Costalos, Neonatal Intensive Care Unit and Department of Ultrasonography, Regional General Hospital of Piraeus, Greece 
P Kokori, L Varchalama, Department of Ultrasonography, Regional General Hospital of Piraeus

M Skouroliakou, Charokopion University, Athens, Greece

\section{REFERENCES}

1 Lucey JF. The xanthine treatment of apnea of prematurity. Pediatrics 1975:55:584-6.

2 Peliowski A, Finer NN. A blinded, randomized placebo-controlled trial to compare theophylline and Doxapram for treatment of apnea of prematurity J Pediatr 1990; 1 16:648-53.

3 Sims ME, Yan G, Rambhatla $S$, et al. Limitations of theophylline in the treatment of apnea of prematurity. Am J Dis Child 1985; 139:567-70.

4 Becker HV, Duc G. Does caffeine prevent hypoxaemic episodes in prematures infants? a randomized control trial. Eur J Pediatr 1988;147:288-91.

5 Levitt GA, Mushim A, Bellman S, et al. Outcome of preterm infants who suffered neonatal apnoeic attacks. Early Hum Dev 1988;16:235-43.

6 Greenough A, Elias-Jones A, Pool J, et al. The therapeutic actions of theophylline in preterm ventilated infants. Early Hum Dev 1985;12:15-22.

7 Lounghnan PM, McNamara JM. Paroxysmal supraventricular tachycardia during theophylline therapy in a premature infant. J Pediatr 1978;92:1016-18.

8 Yeh TF, Pildes RS. Transplacental aminophylline toxicity in a neonate. Lancet 1977;23/4:910.

9 Barter B, Roberts RJ. Unusual case of aminophylline intoxication. Pediatrics 1973;52:602-9.

10 Zwilich CW, Sutton FD Jr, Naff TA, et al. Theophylline induces seizures in adults: correlation with serum concentrations. Ann Intern Med 1975;82:784-7.

11 Warszawski D, Corodisher R, Kaplanski J. Comparative toxicity of caffeine and aminophylline (theophylline ethylenediamine) in young and adult rats. Biol Neonate 1978;34:68-71.

12 Wells $\mathbf{H}$, Lloyd W. Inhibition of the hypocalcemic action of thyrocalcitonin by theophylline and isoproterenol. J Endocrinol 1978;82:468-74.

13 Hollo I. Intravenous aninophylline and osteoporosis [letter to the editor] Lancet 1973;2:1203.

14 Stein MR, Weber RW, Townor TG. The effect of theophylline on the lower esophageal sphincter pressure (LESP) [abstract]. J Allergy Clin Immunol 1978;6:137.
15 Riezzo G, Indrio F, Montagna $O$, et al. Gastric electrical activity and gastric emptying in preterm newborns fed standard and hydrolysate formulas. J Pediatr Gastroenterol Nutr 2001;33:290-5.

16 Kulik W, Van Weissenbruch MM, Menelik N, et al. Improved use of the $\left({ }^{13} \mathrm{C}\right)$ octanoic acid breath test as intraindividual parameter to study the effect of a prokinetic drug on gastric emptying in preterm infants with oral feeding intolerance. J Chromatogr B Biomend Sci Appl 2001;5:750147-53.

17 Newells S, Chapman S, Booth I. Ultrasonic assessment of gastric emptying in the preterm infant. Arch Dis Child 1993:69:32-6.

18 Henderson-Smart DJ, Streer P. Methylxanthine treatment for apnea in preterm infants (Cochrane Review). Cochrane Library, Issue 7. Oxford: Update Software, 1999

19 Henderson-Smart DJ, Steer P. Prophylactic methylxanthine for the prevention of apnea in preterm infants (Cochrane Review). Cochrane Library, Issue 1. Oxford: Update Software, 1999.

20 Henderson-Smart DJ, Davis PG. Prophylactic methylxanthine for extubation in preterm infants (Cochrane Review). Cochrane Library, Issue 4. Oxford: Update Software, 1997.

21 Peyds O, Schneider. Aminophylline reduces cerebral blood flow in stable, preterm infant without affecting the visual evoked potential. Eur J Pediatr $1991 ; 150: 366-9$

22 Waxler SH, Schack JA. Administration of aminophylline (theophylline ethylenediamine). JAMA 1950;143:736-9.

23 Jacobs MH, Senior RM, Kessler G. Clinical experience with theophylline, relationships between dosage, serum concentration and toxicity. JAMA 1976;235:1983-6.

24 McKenzie SA, Baillie E, Godfrey S. Effect of practical timing of dosage on theophylline blood levels in asthmatic children treated with choline theophyllinate. Arch Dis Child 1978;53:167-8.

25 Yeh TF, Pildes RS. Transplacental aminophylline toxicity in a neonate. Lancet 1977;23:910.

26 Grosfeld JL, Dalsing MC, Hull M, et al. Neonatal apnea, xanthines and necrotizing enterocolitis. J Pediatr Surg 1983;18:1.

27 Hufuai-Miller CA, Blackmon L, Baumgart S, et al. Enteral theophylline and necrotizing enterocolitis in the low-birthweight infant. Clin Pediatr 1993; 11:647-53.

28 Foster L, Trudeau WL, Goldman AL. Bronchodilator effects on gastric acid secretion. JAMA 1979;241:2613-15.

29 Pfaffman MA, McFarland SA. Relationship between theophylline-induced relaxation and excitation. Contraction coupling in intestinal smooth muscle. Arch Int Pharmacodyn 1978;232:180-91. 